\title{
FÓRUM
}

Submetido 30.05.2020. Aprovado 02.02.2021

Avaliado pelo sistema double blind review. Editores convidados: Luciana Marques Vieira, Marcia Dutra de Barcellos, Gustavo Porpino de Araujo, Mattias Eriksson, Manoj Dora e Daniele Eckert Matzembacher

Versão original | DOI: http://dx.doi.org/10.1590/S0034-759020210504

\section{PROCRASTINAÇÃO, CONTROLE E ESFORÇO PERCEBIDO NO COMPORTAMENTO DE DESPERDÍCIO DE ALIMENTOS}

\author{
Procrastination, control and perceived effort in food waste behaviour \\ Procrastinación, control y esfuerzo percibido en el comportamiento de desperdicio de alimentos
}

Marconi Freitas da $\operatorname{Costa}^{1}$ | marconi.fcosta@ufpe.br | ORCID: 0000-0001-9888-8359

Patrícia de Oliveira Campos ${ }^{1}$ | patriciadeocampos@gmail.com | ORCID: 0000-0001-9304-9337

Poliana Nunes de Santana² | pndesantana@gmail.com | ORCID: 0000-0003-2039-9496

1Universidade Federal de Pernambuco, Programa de Pós-Graduação em Gestão, Inovação e Consumo, Caruaru, PE, Brasil

¿Universidade Federal de Pernambuco, Programa de Pós-Graduação em Administração, Recife, PE, Brasil

\section{RESUMO}

O desperdício de alimentos pode ser observado em toda a indústria alimentícia, refletindo em efeitos negativos nas esferas social, ambiental e econômica. Este estudo objetiva contribuir para a identificação dos fatores preditores desse comportamento, especificamente, relacionando a propensão a procrastinar e as variáveis controle de alimentos e esforço percebido como mediadoras do comportamento em relação ao desperdício de alimentos. Para tanto, foi realizada uma coleta por meio de survey on-line, com uma amostra final de 279 respondentes, e as hipóteses foram analisadas com a modelagem de equações estruturais (MEE). Como principais resultados, destaca-se que a procrastinação não se mostrou significativa para explicar o comportamento de desperdício de alimentos, e o controle desses produtos reduz a percepção de esforço. Além disso, elucida-se que um maior controle realizado de maneira intuitiva é contraproducente. Como uma das principais contribuições gerenciais deste estudo, ressalta-se a urgência por difusão de cartilhas e treinamentos com o objetivo de disseminar técnicas de controle de alimentos e acessibilidade às informações sobre o período de durabilidade dos produtos alimentícios.

PALAVRAS-CHAVE | Procrastinação, controle de alimentos, esforço percebido, desperdício de alimentos, comportamento do consumidor.

\section{ABSTRACT}

Food waste can be observed in the entire food industry, and it negatively impacts the social, environmental and economic spheres. This study aims to identify the predictive factors for such behavior, specifically those relating the propensity to procrastinate, and the "food control" and "perceived effort" variables as mediators of food waste behavior. To this end, data were collected by way of an online survey, resulting in a consistent final sample of 279 respondents, with the hypotheses being analyzed by structural equation modeling. As the key results of this study, procrastination was not significant for explaining food waste behavior, while food control reduces perceived effort. This study has also clarified that greater, intuitive control is counterproductive. As for its contributions to management, the urgent need to use booklets and training to disseminate food control techniques and access to information on the shelf life of food products stands out.

KEYWORDS / Procrastination, food control, perceived effort, food waste, consumer behavior.

\section{RESUMEN}

El desperdicio de alimentos se puede observar en toda la industria alimentaria, reflejando efectos negativos en los ámbitos social, ambiental y económico. Este estudio tiene como objetivo contribuir a la identificación de los factores predictivos de esta conducta, en concreto, relacionando la propensión a procrastinar y las variables control alimentario y esfuerzo percibido como mediadoras de la conducta en relación al desperdicio alimentario. Para ello, se realizó una recolección a través de una encuesta online, con una muestra final de 279 encuestados y se analizaron las hipótesis con la modelización de ecuaciones estructurales. Como principales resultados, se destaca que la procrastinación no fue significativa para explicar el comportamiento del desperdicio de alimentos, y que el control de estos productos reduce la percepción de esfuerzo. Además, se aclara que un mayor control realizado de forma intuitiva es contraproducente. Como una de las principales contribuciones gerenciales de este estudio, se enfatiza la necesidad urgente de difusión de folletos y capacitación para difundir técnicas de control de alimentos y acceso a información sobre la durabilidad de los alimentos.

PALABRAS CLAVE I Procrastinación, control de alimentos, esfuerzo percibido, desperdicio alimentario, comportamiento del consumidor. 


\section{INTRODUÇÃO}

O desperdício de alimentos apresenta efeitos contraproducentes nas esferas econômica, social e ambiental (Patra, Leisnham, Tanui, \& Pradham, 2020). Esse fenômeno é intrínseco ao aumento da fome, da emissão de gases que provocam efeito estufa, da degradação da biosfera e da escassez de recursos naturais - especialmente, de água -, além de repercutir em limitações na produção de determinados alimentos para as gerações futuras (Stancu, Haugaard, \& Lähteenmäki, 2016).

A Food and Agriculture Organization of the United Nations (FAO, 2018) aponta que um terço de tudo o que é produzido é desperdiçado em algum momento do processo produtivo e de consumo. Assim, há perda substancial em termos financeiros, ultrapassando 900 bilhões de dólares por ano, o que repercute em minimização da segurança alimentar das famílias, no aumento da inflação do mercado alimentício e na diminuição do poder de compra (FAO, 2018; Papargyropoulou, Lozano, Steinberger, Wright, \& Ujang, 2014).

Com vistas a compreender os propulsores desse comportamento, alguns pesquisadores têm empenhado esforços nesse sentido, principalmente, a partir da criação de modelos teóricos, utilizando como ponto de partida a Teoria do Comportamento Planejado (TCP) (e.g. Neubig et al., 2020; Stancu et al., 2016). Apesar da contribuição teórica e prática dessas pesquisas, algumas questões ainda não se encontram claras e precisam ser respondidas por meio da construção de um modelo teórico independente à TCP. Por isso, esta pesquisa desvincula-se dessa matriz e objetiva criar um modelo teórico original e preditivo.

Até o momento, a literatura aponta fortes indícios de que uma das principais causas do desperdício está relacionada à compra em excesso de produtos (Amirudin \& Gin, 2019), combinada, especialmente, à falta de gerenciamento adequado dos alimentos (Aschemann-Witzel, Giménez, \& Ares, 2019). Todavia, os fatores que explicam a ausência de motivação em realizar o controle de alimentos de maneira apropriada ainda não estão totalmente estabelecidos.

O controle são ações de gerenciamento dos alimentos que os indivíduos possuem em casa, no sentido de alocá-los de maneira recomendada, consumi-los nos prazos estabelecidos e saber quais estão próximos de expirar (Aitken, Watkins, Williams, \& Kean, 2020). Contudo, há negligência dessa atividade (Graham-Rowe, Jessop, \& Sparks, 2014), pois requer dos consumidores conscientização, dedicação e esforço, tornando os custos altos (Aschemann-Witzel et al., 2019). Assim, este estudo sugere que uma das causas desse comportamento pode estar vinculada à procrastinação dos consumidores em empenhar-se em atividades dessa natureza.

A procrastinação refere-se à tendência de adiar ou evitar o cumprimento de certas atividades, especialmente as de menor impacto imediato (Steel, 2010). Nesse sentido, ela tende a acentuar-se quando relacionada a causas sustentáveis, uma vez que estas não apresentam um retorno claro, reduzindo, inclusive, o efeito positivo da conscientização ambiental (Lillemo, 2014).

Em outra perspectiva, o estudo de Porpino, Wansink e Parente (2016) indica a procrastinação como uma das dimensões do desperdício ao mostrar como as famílias lidam com sobras, deixando-as armazenadas até que estraguem e possam ser descartadas sem remorso. Blichfeldt, Mikkelsen e Gram (2015), de modo semelhante, apontam que quanto mais as pessoas adiam o descarte, mais fácil se torna fazê-lo, visto que o alimento deixa de ser apropriado ao consumo, diminuindo o sentimento de culpa pelo desperdício.

Além disso, outra variante que pode ser explicativa é o esforço percebido, sobretudo, em termos do "trabalho duro" empregado na produção dos alimentos de consumo próprio, pois, como sugerem Dobernig e Schanes (2019), o investimento de tempo e recursos nesse processo gera um valor simbólico. Isso posto, espera-se que a probabilidade de gerenciamento e aproveitamento total de alimentos seja maior quando as pessoas preparam sua própria comida. 
Diante do exposto, esta pesquisa busca contribuir para o avanço da compreensão desse fenômeno ao analisar se há relação do comportamento de procrastinação do consumidor sobre o comportamento em relação ao desperdício de alimentos, avaliando também como as características dos indivíduos de controle de alimentos e de esforço percebido interferem e são afetadas nessa relação. Destarte, esta pesquisa faz a proposição de um modelo teórico explicativo e busca analisar a significância dessa coadunação.

\section{REFERENCIAL TEÓRICO}

\section{Desperdício de alimentos}

O desperdício de alimentos pode ser definido como a prática de descartar alimentos adequados ao consumo humano, ocasionada pela negligência do consumidor, que deixa os produtos ultrapassarem a data de validade ou não os aproveita na totalidade (FAO, 2018). Ele impacta fatores éticos e sustentáveis e relaciona-se ao perfil dos consumidores no tocante aos seguintes aspectos: psicológicos, demográficos e culturais (Radzyminska, Jakubowska, \& Staniewska, 2016). Tendo isso em vista, pesquisadores têm, diligentemente, buscado desenvolver estudos a fim de compreender os antecedentes que levam os indivíduos ao desperdício.

A pesquisa de Aktas et al. (2018), por exemplo, tem seus resultados fundamentados em aspectos ligados à educação financeira, ao gerenciamento da rotina, ao processo de cozinhar e consumir alimentos em excesso, bem como em aspectos ligados a influências sociais. Além disso, sabe-se que aspectos psicológicos e sociodemográficos influenciam o desperdício de alimentos, embora esses últimos apresentem baixo potencial explicativo (Aschemann-Witzel, Hooge, Amani, Bech-Larsen, \& Oostindjer, 2015).

Outrossim, ao utilizar o modelo teórico da TCP, Russell, Young, Unsworth e Robinson (2017) contribuem, especificamente, para a identificação dos fatores psicológicos. Assim, apontam que normas subjetivas, controle de comportamento percebido e intenção, além de hábitos e emoções, possuem relação direta com o desperdício de alimentos. Por sua vez, de modo dissonante ao que apontam Aschemann-Witzel et al. (2015), o estudo de Stancu et al. (2016) revela que os aspectos sociodemográficos exercem alta influência no desperdício. Os autores elucidam que indivíduos com idade mais avançada, família pequena e menor renda tendem a desperdiçar menos. Em contrapartida, países desenvolvidos, com maior renda per capita, representam maior parcela de desperdício. Nessa ótica, Carmo e Barcellos (2018) elucidam que indivíduos de baixa renda estão menos propensos a esse comportamento.

Em contraste, Woensel, Donselaar, Broekmeulen e Fransoo (2007) explanam que famílias de baixa renda e com menor escolaridade tendem a desperdiçar mais devido à necessidade de exibir status por meio do excesso de alimentos, bem como casas que possuem maior número de crianças. Os achados de Porpino et al. (2016) apontam que os pais aspiram a ser vistos pelos filhos como bons e tendem a simbolizar tal desejo por meio da proveniência de alimentos, materializando-o na compra e estoque de produtos em excesso.

É interessante enfatizar que, mesmo conscientes dos efeitos do desperdício, os consumidores não se sentem impactados por isso, e seus comportamentos continuam imprudentes (Radzyminska et al., 2016). Assim, além dos antecedentes supracitados, apontam-se, ainda, outros fatores que fomentam esse comportamento, a saber: aspectos morais do indivíduo (Raats, Shepherd, \& Sparks, 1995); habilidades de cozinhar (Hartmann, Dohle, \& Siegrist, 2013); compra em excesso e compra compulsiva (Porpino, Parente, \& Wansink, 2015); não reutilização das sobras (Stancu et al., 2016); sentimento de culpa (Richter, 2017); e valores materialistas (Abdelradi, 2018). 
Este estudo busca expandir esses achados correlacionando as variáveis procrastinação, controle de alimentos e esforço percebido como fatores explicativos do desperdício. Tais tópicos são abordados a seguir.

\section{Procrastinação}

Conforme Parfenova e Romashova (2019), a procrastinação compreende um atraso na realização de atividades, sem razões contundentes que justifiquem isso, que incorre em um desconforto psicológico. Assim, ela é caracterizada como uma tendência a adiar a conclusão de um determinado objetivo (Zanjani, Milne, \& Miller, 2016) e está pautada na ausência de autocontrole, o que afeta especialmente atividades que apresentam retorno futuro abstrato (Chen, Liu, Zhang, \& Feng, 2020).

Como observado na pesquisa de Akerlof (1991), um dos fatores explicativos desse comportamento é a mudança na relação entre custos e benefícios conforme o decorrer do tempo. Assim, quando uma tarefa é estabelecida, os custos são interpretados como pequenos, porém, posteriormente, eles tornam-se maiores e os benefícios, mais abstratos. Nesse sentido, a postergação de atividades reverbera em alto custo cognitivo, psicológico e social (Liu, Cheng, Hu, Pan, \& Zhao, 2020).

As consequências da procrastinação refletem, ainda, nas esferas econômica e ambiental. Nessa perspectiva, Lillemo (2014) assinala que indivíduos com propensão procrastinadora tendem a evitar o engajamento em atividades relacionadas a causas sustentáveis, sobretudo quando estas requerem esforço psicológico e monetário, pois os ganhos futuros ligados a elas comumente são vistos como de menor impacto no presente. Isso pode incorrer na desvalorização do investimento de recursos em ações pró-ambiente e em redução do efeito positivo da conscientização ambiental.

Outrossim, Zhu, Bagchi e Hock (2019) explicam a lógica do comportamento e sua relação com o custo do atraso das tarefas, apontando que quanto mais distante o prazo, menor a percepção do custo e maior a probabilidade de procrastinar. Além disso, como a produtividade é vislumbrada como um valor (Gamst-Klaussen, Steel, \& Svartdal, 2019), os indivíduos tendem a buscar um conforto psicológico ao iniciar a realização de tarefas não por ordem de prioridade, mas de acordo com seu grau de complexidade. Assim, iniciam por aquelas que requerem menor esforço (Rusou, Amar, \& Ayal, 2020).

Nesse contexto, os estudos de Blichfeldt et al. (2015) e de Porpino et al. (2016) introduzem discussões relacionadas à procrastinação, no contexto de desperdício de alimentos, como forma de reduzir e mitigar a culpa e o remorso pelo descarte. Os dois trabalhos demonstram que indivíduos que procrastinam tendem a guardar sobras das refeições até que elas estraguem, tornando-se inapropriadas ao consumo humano e despertando sentimentos de aversão e nojo, o que faz do descarte um comportamento inevitável e, portanto, livre de culpas.

Com base nos achados supracitados, os quais foram provenientes de estudos exploratórios, percebe-se que a procrastinação pode atuar como preditora do comportamento de desperdício de alimentos. Com vistas a mensurar essa influência, a seguinte hipótese foi elaborada:

H1: Quanto maior o comportamento de procrastinar, maior será o comportamento de desperdiçar alimentos.

\section{Controle de alimentos}

0 controle de alimentos pode ser definido como a gestão adequada de estoque e sobras de refeições (Masson, Delarue, \& Blumenthal, 2017). Esse processo engloba, sobretudo, a armazenagem em condições adequadas e o monitoramento constante de produtos disponíveis no âmbito familiar com vistas a evitar o não aproveita- 
mento dos alimentos em sua totalidade, perdas nutricionais e riscos à saúde (Holsteijn \& Kemna, 2018). Para tanto, requer-se sensibilidade para identificar se os alimentos continuam, de fato, próprios ao consumo, além de checar e interpretar de maneira correta os rótulos das embalagens, que apresentam os meios adequados de manuseio (Kavanaugh \& Quinlan, 2020).

$\mathrm{Na}$ literatura desse construto, pode-se observar uma linha a qual defende que conhecer técnicas adequadas de armazenagem de produtos possibilita a diminuição do desperdício de alimentos (e.g. Graham-Rowe et al., 2014; Schanes, Dobernig, \& Gözet, 2018) e, também, que a convicção de possuir competência para gerenciá-los tem uma alta influência no seu controle (Dobernig \& Schanes, 2019). Todavia, percebe-se uma dissonância no campo, uma vez que, conforme apontam Terpstra, Steenbekkers, Maertelaere e Nijhuis (2005) e Dobernig e Schanes (2019), apesar de os participantes de suas investigações conhecerem as diretrizes de armazenagem e afirmarem realizar um controle adequado, possuíam alimentos armazenados por um tempo superior ao recomendado.

Tal fato posto, mantém-se válida a afirmação de que os consumidores não conseguem gerenciar de modo eficaz os alimentos (Farr-Wharton, Foth, \& Choi, 2014). Isso ocorre, principalmente, devido à falta de uma rotina sistemática de controle e de organização (Costa, Farias, \& Angelo, 2018; Romani, Grappi, Bagozzi, \& Barone, 2018), pois, mesmo realizando o controle, os consumidores esquecem os produtos, resultando no desperdício (Dobernig \& Schanes, 2019). Os indivíduos recordam-se dos produtos armazenados apenas quando há a necessidade de algum item para o preparo de uma refeição ou quando se separa um tempo para checá-los e organizá-los, percebendo, então, que se encontram inapropriados ao consumo (Aschemann-Witzel et al., 2019).

Portanto, apesar dos esforços em compreender como o controle de alimentos influencia a diminuição do desperdício, seu potencial de explicação ainda não está totalmente claro. Isso ocorre sobremaneira porque, mesmo os consumidores sabendo as recomendações para armazenagem correta de alimentos, eles não seguem as orientações sugeridas (Marklinder, Lindblad, Eriksson, Finnson, \& Lindqvist, 2004). Com base nisso, busca-se contribuir para a literatura por meio da mensuração do potencial explicativo do controle de alimentos na diminuição do desperdício. Assim, propõe-se a seguinte hipótese:

H2: Quanto maior o controle de alimentos, menor será o comportamento de desperdício de alimentos.

Apesar da relevância da gestão correta dos alimentos para aumentar seu tempo de vida útil, Farr-Wharton et al. (2014) revelam que uma grande quantidade de famílias não a realiza. Entende-se que tais consumidores não estão voltados para essas ações por visualizarem suas consequências distantes, não ponderarem e possuírem conhecimento dos reflexos diretos nas suas vidas. Além disso, Blichfeldt et al. (2015) apontam que há envolvimento das dimensões da procrastinação no desperdício de alimentos, pois os indivíduos permanecem em estado de inércia diante da reutilização de sobras, ultrapassando o tempo recomendado. Além disso, um dos recursos utilizados para armazenar os alimentos e aumentar seu tempo para consumo é a geladeira, todavia a utilização dessa tecnologia mostra-se como copartícipe da procrastinação (Evans, 2011). Assim, propõe-se a seguinte hipótese:

H3: Quanto maior o comportamento de procrastinar, menor será o controle de alimentos.

\section{Esforço percebido}

Como supracitado, diversas variáveis - endógenas e/ou exógenas - concorrem à realização das práticas humanas cotidianas (Langan \& Kumar, 2019). Convém destacar o esforço, o qual é conceituado por Brehm, Wright, Solomon, Silka e Greenberg (1983) como a percepção acerca dos comportamentos que devem ser empregados no alcance de 
objetivos. Mohr e Bitner (1995) também contribuem para formação desse construto ao abordá-lo como a medida de energia necessária ao exercício de uma tarefa ou de um conjunto delas. Para os fins deste estudo, a definição adotada será a de Modig, Dahlén e Colliander (2014), devido à sua especificidade. Assim, o esforço, aqui, refere-se ao tempo, aos recursos e ao "trabalho duro" gastos no cumprimento de tarefas.

Ao observarem os indivíduos como Homo economicus, os pesquisadores (e.g. Hesse, Kangur, \& Hunt, 2020; Zeelenberg \& Dijk, 1997), que estudam as teorias econômicas do processo de decisão, defendem que o esforço percebido diminui ou neutraliza o valor da recompensa e, assim, pode causar aversão à tarefa. Como elucidam Amirudin e Gin (2019), no contexto de compras de supermercado, quanto maior o esforço percebido em termos de deslocamento e tempo empenhado, maiores as chances de buscar meios para evitar realizar as compras. Assim, conforme apontam os autores, os indivíduos tendem a adquirir o máximo de alimentos possível para postergar a necessidade de recompra. Isso resulta em um aumento do desperdício de alimentos.

Todavia, o esforço é um construto paradoxal (Inzlicht, Shenhav, \& Olivola, 2018) e pode, ao invés de diminuir, aumentar o valor de uma atividade (Harmon-Jones, Willoughby, Paul, \& Harmon-Jones, 2020), porquanto o envolvimento do consumidor no processo modera a percepção de esforço (Kallmuenzer, Peters, \& Buhalis, 2019), bem como a criação de valor, dependendo dos recursos envolvidos (Benfer, Bardeen, \& Clauss, 2018). Por exemplo, os recursos de tempo e dinheiro apresentam níveis diferentes de esforço para os indivíduos, pois a doação de tempo gera maior esforço percebido e, consequentemente, maior valor do que a doação de dinheiro (Langan \& Kumar, 2019). No contexto de desperdício de alimentos, Ilyuk (2018) revela que quando há aplicação de trabalho duro por parte dos consumidores, há uma maior valorização do produto e aumento de propriedade psicológica, reduzindo o descarte.

Essa relação positiva entre envolvimento e criação de valor pode ser encontrada, principalmente, na literatura sobre cocriação (e.g. Ahn, Lee, Back, \& Schmitt, 2019; Yen, Teng, \& Tzeng, 2020). 0 processo de produção conjunta é visto como uma estratégia de Marketing, que promove a intenção de compra e estabelece uma relação de confiança (Jacobsen, Tudoran, \& Martinez, 2020). Nessa perspectiva, percebe-se que produtos oriundos de criação participativa do indivíduo tendem a ser supervalorizados (Banović, Krystallis, Guerrero, \& Reinders, 2016). Assim, baseando-se na premissa de que a energia empregada à produção dos alimentos atribui um valor simbólico pelos recursos que exige (Dobernig \& Schanes, 2019), busca-se contribuir para a literatura de esforço e desperdício de alimentos por meio da verificação da seguinte hipótese:

H4: Quanto maior o esforço percebido, menor o comportamento de desperdício de alimentos.

Ao realizar uma tarefa, a justificativa do esforço dá-se quando há uma ligação proporcional com uma recompensa clara, pois, quando esta não depende exclusivamente do esforço, tende a ser pouco valorizada e o esforço, superestimado (Harmon-Jones et al., 2020). Além disso, a busca por evitar perdas possui maior influência na disposição em empenhar esforço do que a obtenção de ganhos (Massar, Pu, Chen, \& Chee, 2020). Assim, pode-se inferir que atividades com foco em ganhos tendem a ser mais procrastinadas.

Essa relação pode ser ainda mais intensificada se os ganhos forem visualizados como abstratos e/ou de menor impacto no presente, como é o caso da realização de atividades sustentáveis (Lillemo, 2014). Como uma das razões para evitar o desperdício de alimentos é obter ganhos ambientalmente (Diaz-Ruiz, Costa-Font, \& Gil, 2018), pode-se inferir que a realização de atividades nesse sentido tende a resultar em um maior esforço percebido, uma vez que o foco está em obter ganhos, e estes representam menor retorno imediato no presente. Com base nisso, supõe-se que quanto maior o comportamento de procrastinar, maior é o esforço percebido para a realização de atividades com vistas a diminuir o desperdício. Para validar essa conjectura, a seguinte hipótese foi elaborada: 
H5: Quanto maior o comportamento de procrastinar, maior será o esforço percebido.

Na literatura sobre o construto controle de alimentos, são encontrados alguns estudos (e.g. Blichfeldt et al., 2015; Porpino et al., 2016; Romani et al., 2018) que demonstram como uma rotina de compras não planejada e a ausência de um modo sistemático de organização e controle podem incorrer em excesso de produtos a serem armazenados. Isso resulta em um não controle eficaz dos alimentos e, consequentemente, no desperdício (Farr-Wharton et al., 2014).

Diante disso, inicia-se um novo ciclo de necessidade de realização de compras para garantir a alimentação (Hebrok \& Boks, 2017). 0 acesso e tempo requeridos nesse processo podem moderar o esforço percebido e o custo de oportunidade de não compra. Ou seja, quando a aquisição de produtos intercepta percalços de locomoção e requer maior empenho de tempo, seu processo é percebido como custoso, e, assim, uma forma de compensá-lo dá-se por meio da aquisição de uma maior quantidade de produtos (Lee, 2018).

0 estudo de Amirudin e Gin (2019) ilustra bem essa relação ao elucidar como questões relativas à facilidade de acesso aos alimentos permeiam a percepção de esforço e a aversão à atividade. Assim, eles apontam que quanto maior o esforço percebido, maior o excesso de compras. Nesse sentido, a facilidade de acesso aos produtos, tanto em termos de disponibilidade de horários quanto de distância física dos locais de aquisição, reflete-se em compras de alimentos em menor quantidade (Dobernig \& Schanes, 2019) e, desse modo, favorece um controle efetivo de alimentos. Isso posto, pode-se inferir que o maior controle de alimentos se associa a um menor esforço percebido. Para testar essa conjectura, a seguinte hipótese foi desenvolvida:

H6: Quanto maior o controle de alimentos, menor será o esforço percebido.

Para melhor visualização do modelo teórico aqui proposto, apresenta-se a Figura 1. É possível perceber o estabelecimento da relação preditora da procrastinação com o controle dos alimentos, esforço percebido e comportamento em relação ao desperdício de alimentos, bem como a vinculação mediadora do controle de alimentos e esforço percebido em relação ao comportamento de desperdício.

\section{Figura 1. Modelo teórico}

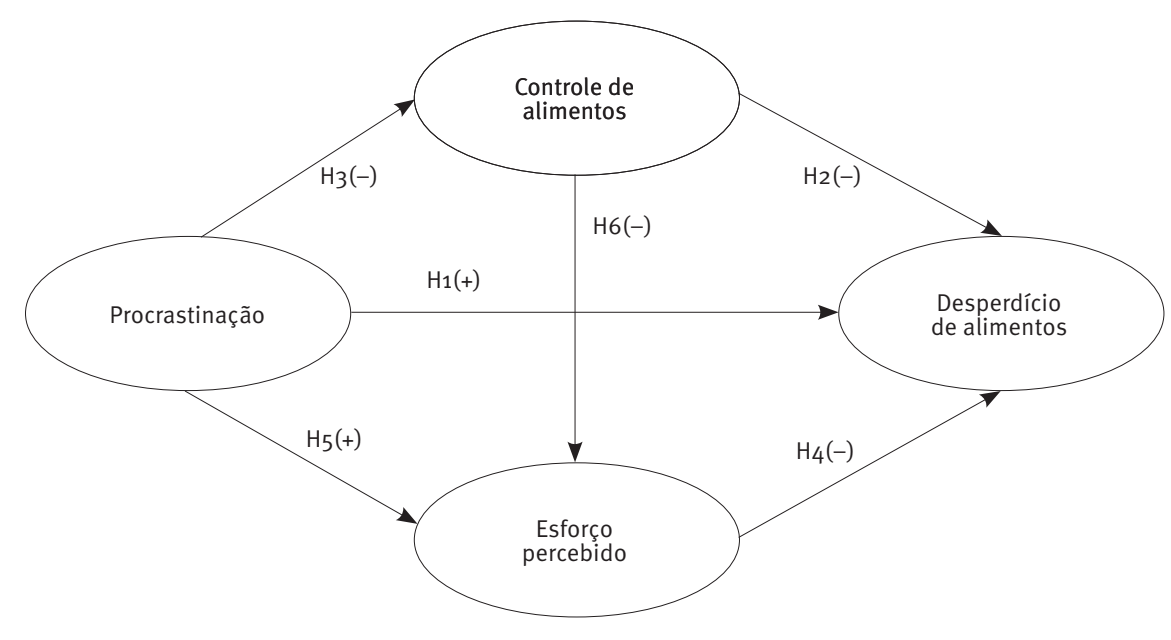




\section{MÉTODO}

Este estudo é de natureza quantitativa e busca desenvolver um modelo explicativo para o comportamento em relação ao desperdício de alimentos. Caracteriza-se como uma pesquisa descritiva (Malhotra, 2012), baseando-se na formulação de hipóteses. Primeiramente, realizou-se uma revisão da literatura nas seguintes bases de dados: ScienceDirect, Scopus, Proquest e Scielo. Em seguida, para levantamento dos dados, utilizou-se, conforme orienta Churchill (1999), o método de levantamento de corte transversal - cross-sectional survey - e, para análise das relações entre as variáveis, adotou-se a modelagem de equações estruturais (MEE) (Kline, 2011).

\section{Seleção da amostra}

Para a amostra deste estudo, buscou-se obter uma maior heterogeneidade para melhor validação dos resultados. Esta é composta por consumidores brasileiros e caracteriza-se como não probabilística (Hair, Anderson, Taham, \& Black, 2010). Conquanto, para garantir eficácia na avaliação do comportamento de desperdício de alimentos, foram criados critérios para os respondentes. Assim, permaneceram na amostra consumidores categorizados como jovens (18-40 anos), uma vez que consumidores mais velhos tendem a desperdiçar menos (Stancu et al., 2016), bem como os que possuem uma prospecção de ascender de classe social, ou seja, que possuem ou estão cursando o ensino superior, pois estes são mais propensos ao desperdício (Aschemann-Witzel et al., 2019).

Isso posto, o tamanho da amostra foi definido com base na orientação de Hair et al. (2010) de ter, pelo menos, cinco respondentes para cada pergunta do questionário e seguindo as recomendações de Tanaka (1987) para o tamanho de amostra com o uso de MEE, de modo a não exceder 400 respondentes. Assim, foram definidas duas amostras, a primeira para refinar o questionário - com 140 respondentes - e a segunda para testar as hipóteses, que inicialmente possuía 310 respondentes, mas foi necessária a exclusão de 31 questionários que não se enquadraram nos critérios supracitados, sendo a amostra final para testar as hipóteses de 279 participantes.

\section{Coleta dos dados}

A coleta de dados foi realizada por meio de survey com base num questionário estruturado tipo Likert, contendo 30 questões, onde o respondente indicou o grau de concordância com as afirmativas. A técnica utilizada foi snowball sampling. A coleta ocorreu durante o mês de fevereiro de 2020. 0 questionário foi aplicado on-line por meio do Google Forms, dividido em cinco seções: Procrastinação (16 itens), Controle de Alimentos (três itens), Esforço Percebido (quatro itens), Desperdício de Alimentos (sete itens) e, por fim, perfil do respondente, com seis questões: sexo, idade, estado civil, escolaridade, renda familiar mensal média e total de pessoas residentes na casa. Importante destacar que, para a análise, os itens da escala de Procrastinação foram invertidos. 0 Quadro 1 descreve os itens apresentados em cada construto. 
Quadro 1. Escalas utilizadas na pesquisa

\begin{tabular}{|c|c|c|}
\hline Dimensões & Itens & Códigos \\
\hline \multirow{16}{*}{$\begin{array}{l}\text { Procrastinação } \\
\text { Adaptada de Tuckman } \\
\text { (1990) }\end{array}$} & $\begin{array}{l}\text { Q1. Atraso desnecessariamente para finalizar trabalhos, mesmo quando são } \\
\text { importantes. }\end{array}$ & Po1 \\
\hline & Q2. Adio as coisas que não gosto de fazer. & Po2 \\
\hline & Q3. Atraso na tomada de decisões difíceis. & Po3 \\
\hline & Q4. Continuo adiando a melhoria dos meus hábitos de trabalho. & Po4 \\
\hline & Q5. Eu vou direto ao trabalho, mesmo nas tarefas desagradáveis da vida.* & P05 \\
\hline & Q6. Consigo encontrar uma desculpa para não fazer algo. & Po6 \\
\hline & Q7. Eu dedico o tempo necessário a tarefas mais chatas, como estudar.* & Po7 \\
\hline & Q8. Quando algo não vale a pena, eu paro. & Po8 \\
\hline & Q9. Eu sou um incurável desperdiçador de tempo. & Pog \\
\hline & $\begin{array}{l}\text { Q10. Eu sou um desperdiçador de tempo, mas não consigo fazer nada a } \\
\text { respeito. }\end{array}$ & $\mathrm{P} 10$ \\
\hline & Q11. Eu gostaria de encontrar uma maneira fácil de começar a produzir. & $P_{11}$ \\
\hline & Q12. Sempre termino trabalhos importantes com tempo de sobra* & $\mathrm{P}_{12}$ \\
\hline & Q13. Quando termino meu trabalho, verifico-o.* & $\mathrm{P}_{13}$ \\
\hline & Q14. Eu procuro uma brecha ou atalho para passar uma tarefa difícil. & $\mathrm{P} 14$ \\
\hline & $\begin{array}{l}\text { Q15. Ainda fico em ponto morto, apesar de saber o quanto é importante } \\
\text { começar. }\end{array}$ & $\mathrm{P} 15$ \\
\hline & Q16. Adiar algo até amanhã não é o que faço.* & $\mathrm{P} 16$ \\
\hline \multirow{3}{*}{$\begin{array}{l}\text { Controle de Alimentos } \\
\text { Adaptado de Russell et al. } \\
\text { (2017) }\end{array}$} & Q17. Quanto controle você tem a respeito dos alimentos na sua casa? & $\mathrm{CA}_{1}$ \\
\hline & Q18. Quão difícil seria para você controlar os alimentos na sua casa? & $\mathrm{CA} 2$ \\
\hline & Q19. Depende principalmente de mim controlar os alimentos na minha casa. & $\mathrm{CA}_{3}$ \\
\hline \multirow{4}{*}{$\begin{array}{l}\text { Esforço Percebido } \\
\text { Adaptado de } \\
\text { Aktas et al. (2018). }\end{array}$} & Q20. Acho difícil armazenar comida em altas temperaturas. & $\mathrm{EP} 1$ \\
\hline & Q21. Acho difícil armazenar comida em condições exigidas. & $\mathrm{EP} 2$ \\
\hline & Q22. Acho difícil armazenar alguns tipos específicos de alimentos. & $\mathrm{EP}_{3}$ \\
\hline & Q23. Acho difícil comprar alimentos para uma pessoa. & $\mathrm{EP}_{4}$ \\
\hline \multirow{7}{*}{$\begin{array}{l}\text { Desperdício de Alimentos } \\
\text { Adaptado de } \\
\text { Kameke e Fischer (2018) } \\
\text { e Aktas et al. (2018) }\end{array}$} & Q24. É importante para mim evitar o desperdício de alimentos domésticos. & $\mathrm{DA} 1$ \\
\hline & Q25. Gostaria de fazer mais para evitar o desperdício de alimentos em casa. & $\mathrm{DA} 2$ \\
\hline & $\begin{array}{l}\text { Q26. Eu geraria menos desperdício de alimentos se planejasse minhas } \\
\text { compras com mais cuidado. }\end{array}$ & $\mathrm{DA}_{3}$ \\
\hline & Q27. Eu desperdiço comida quando saio com amigos/família & DA4 \\
\hline & Q28. Eu desperdiço comida quando tenho convidados em casa. & $\mathrm{DA}_{5}$ \\
\hline & Q29. Eu desperdiço comida no trabalho/escola. & DA6 \\
\hline & Q30. Eu desperdiço comida em casa sempre que vou viajar. & DA7 \\
\hline
\end{tabular}

Nota. Os itens com (*) da escala de Procrastinação foram considerados reversos. 


\section{Análise dos dados}

Utilizou-se a estatística descritiva (frequência, média e desvio-padrão) para compreensão do perfil da amostra e dos dados coletados na pesquisa. Além disso, avaliou-se o nível de confiabilidade das escalas por meio do alfa de Cronbach, sendo aceito o nível de confiabilidade maior ou igual a 0,7 (Kline, 2011). Os softwares utilizados para processamento dos dados foram SPSS e AMOS. Como forma de checagem das hipóteses, adotou-se a MEE.

No intuito de refinar o questionário e avaliar os itens em cada construto, para verificar se carregavam em um único fator, foi realizada análise fatorial exploratória (AFE) numa primeira amostra, totalizando 140 respondentes.

Tabela 1. Itens dos construtos com cargas fatoriais

\begin{tabular}{|c|c|c|c|c|c|c|c|c|c|}
\hline \multirow{3}{*}{$\begin{array}{l}\text { Código } \\
\text { P15 }\end{array}$} & \multirow{2}{*}{\multicolumn{4}{|c|}{ Cargas Fatoriais }} & \multirow{2}{*}{ KMO } & \multicolumn{3}{|c|}{ Bartlett } & \multirow{2}{*}{ Cronbach } \\
\hline & & & & & & df & $x^{2}$ & Sig & \\
\hline & 0,780 & & & & \multirow{12}{*}{0,834} & \multirow{12}{*}{120} & \multirow{12}{*}{725,232} & \multirow{12}{*}{0,000} & \multirow{12}{*}{0,864} \\
\hline P02 & 0,763 & & & & & & & & \\
\hline P01 & 0,756 & & & & & & & & \\
\hline $\mathrm{P}_{10}$ & 0,756 & & & & & & & & \\
\hline Pog & 0,725 & & & & & & & & \\
\hline Po4 & 0,702 & & & & & & & & \\
\hline P03 & 0,647 & & & & & & & & \\
\hline Po6 & 0,555 & & & & & & & & \\
\hline $\mathrm{P}_{14}$ & 0,494 & & & & & & & & \\
\hline $\mathrm{P}_{12}$ & 0,465 & & & & & & & & \\
\hline$P_{11}$ & 0,456 & & & & & & & & \\
\hline $\mathrm{P}_{16}$ & 0,452 & & & & & & & & \\
\hline$C A_{1}$ & & 0,887 & & & \multirow{3}{*}{0,668} & \multirow{3}{*}{3} & \multirow{3}{*}{125,738} & \multirow{3}{*}{0,000} & \multirow{3}{*}{0,772} \\
\hline $\mathrm{CA}_{2}$ & & 0,820 & & & & & & & \\
\hline $\mathrm{CA}_{3}$ & & 0,801 & & & & & & & \\
\hline $\mathrm{EP}_{3}$ & & & 0,812 & & \multirow{4}{*}{0,712} & \multirow{4}{*}{6} & \multirow{4}{*}{93,179} & \multirow{4}{*}{0,000} & \multirow{4}{*}{0,710} \\
\hline $\mathrm{EP} 2$ & & & 0,751 & & & & & & \\
\hline $\mathrm{EP} 1$ & & & 0,691 & & & & & & \\
\hline EP4 & & & 0,623 & & & & & & \\
\hline $\mathrm{DA}_{1}$ & & & & 0,832 & \multirow{4}{*}{0,746} & \multirow{4}{*}{6} & \multirow{4}{*}{137,494} & \multirow{4}{*}{0,000} & \multirow{4}{*}{0,786} \\
\hline $\mathrm{DA} 2$ & & & & 0,804 & & & & & \\
\hline $\mathrm{DA}_{3}$ & & & & 0,712 & & & & & \\
\hline $\mathrm{DA}_{4}$ & & & & 0,702 & & & & & \\
\hline
\end{tabular}

Com a identificação de baixas cargas fatoriais, ou com valores carregando em outros fatores, alguns itens foram excluídos dos construtos, para obtenção de apenas um fator por construto. Os itens P05, Po7, Po8 e P13 
foram retirados do construto Procrastinação para que tivesse apenas um fator. Cabe destacar que, na escala original de Tuckman (1990), os itens foram considerados com cargas fatoriais a partir de 0,3, e essa condição foi mantida neste artigo para a AFE realizada. Uma possível explicação para a necessidade de retirada dos itens da escala de Procrastinação pode ser relativa à tradução das afirmativas, pois o contexto e a estrutura de alguns itens podem ter uma interpretação diferente para os respondentes de outras nacionalidades, apresentando algum desvio semântico do item da escala original.

Para o construto Desperdício de Alimentos, foram excluídos: DA1, DA2 e DA3. Isso ocorreu porque foram utilizadas duas escalas diferentes para mensurá-lo, com o intuito de verificar se os itens poderiam, eventualmente, carregar em uma única dimensão (fator). Os testes mostraram que as três afirmativas da escala de Kameke e Fischer (2018) apresentavam cargas em um segundo fator, mesmo com a inversão dos itens. Por isso, optou-se por manter apenas os quatro itens da escala de Aktas et al. (2018) para esse construto. Para os construtos de Controle de Alimentos e Esforço Percebido, não foi necessária a retirada de itens. As cargas fatoriais que permaneceram em cada construto podem ser conferidas na Tabela 1.

\section{ANÁLISE E DISCUSSÃO DOS RESULTADOS}

\section{Perfil da amostra}

A amostra é constituída por 279 respondentes, sendo 53,4\% do sexo feminino e 46,6\% do sexo masculino. Quanto ao nível de escolaridade, $63,4 \%$ dos indivíduos possuem ensino superior incompleto, 19,4\% têm pós-graduação, $12,5 \%$ têm ensino superior completo e 4,3\% possuem apenas o segundo grau completo. 0 perfil predominante é de solteiros (82,1\%). Os participantes casados ou em uma relação estável corresponderam a 16,8\%, e 1,1\% estão divorciados/separados. Os intervalos de idade dos respondentes que mais prevaleceram na pesquisa foram: de 18 a 25 anos (69,2\%); de 26 a 32 (23,3\%); e de 33 a 40 (7,5\%). Pode-se destacar, também, que a idade média encontrada foi de 24 anos, variando de 18 a 40 ( $D P=4,820)$. A renda familiar mensal em intervalos teve um maior percentual para dois grupos, com renda de $R \$ 1,00$ a $R \$ 3.000,00(59,9 \%)$ e com renda de $R \$ 3.001,00$ a $R \$ 6.000,00$ (29\%). A respeito da renda familiar média, obteve-se $R \$ 3.506,41$ ( $D P=3,403$ ), e a média de pessoas que moram na mesma casa dos participantes da pesquisa foi de, aproximadamente, três pessoas ( $D P=$ 1,464), obtendo-se, com isso, a renda per capita média de $R \$ 1.414,00$.

\section{Modelo de mensuração}

Como orienta Marôco (2014), para verificar a existência e a remoção de outliers da amostra, foi utilizada a Distância de Mahalanobis ( $\left.D^{2}\right)$, mas nenhuma observação apresentou valores elevados que fosse necessário retirar da análise. Em seguida, foi realizada a análise fatorial do modelo de mensuração. Os resultados encontrados inicialmente, com as primeiras rodadas da análise do modelo de mensuração, sugeriram a retirada de alguns itens dos construtos para que o modelo conseguisse melhores índices de ajustamento. Assim, foram retirados os itens P06, P11, P12, P14 e P16 do construto de Procrastinação; EP4, do construto Esforço Percebido; e CA4, do construto Controle de Alimentos. Após refinar a composição dos itens dos construtos, foi feita uma nova análise, e os índices resultantes do modelo de mensuração foram: $x^{2} / d f(104,084 / 82)=1,269(p=0,050) ; T L I=0,978$; 
$\mathrm{CFI}=0,983 ; \mathrm{NFI}=0,925 ; \mathrm{PCFI}=0,767 ; \mathrm{RMSEA}=0,030 ; \mathrm{PCLOSE}=0,985 ; \mathrm{ECVI}=0,583 ; \mathrm{MECVI}=0$,596. É possível afirmar que os valores apresentam um bom ajustamento do modelo.

Foi empregada a análise de confiabilidade (Cronbach) e composta (CC), bem como a variância média explicada (AVE) para investigar o nível de adequação das escalas de cada construto. 0 alfa de Cronbach acima de 0,7 permite afirmar a consistência interna dos itens em cada escala. É possível observar, na Tabela 2, que todos os construtos têm valores superiores a essa taxa. A confiabilidade composta também tem a definição de um índice igual ou maior que 0,7 (Hair et al., 2010), sendo alcançado por todos os construtos, de acordo com a Tabela 2. 0 cálculo da média e desvio-padrão dos construtos foi realizado para as variáveis que foram criadas por meio do summated scale para essa finalidade.

\section{Tabela 2. Estatística descritiva, confiabilidade e validade}

\begin{tabular}{l|l|l|l|l|l}
\hline Variáveis & Média & D.P. & Cronbach & CC & AVE \\
\hline Procrastinação (P) & 4,42 & 1,37 & 0,835 & 0,885 & 0,529 \\
\hline Controle de Alimentos (CA) & 4,39 & 1,67 & 0,751 & 0,846 & 0,652 \\
\hline Esforço Percebido (EP) & 3,69 & 1,56 & 0,701 & 0,794 & 0,567 \\
\hline Desperdício de Alimentos (DA) & 2,44 & 1,41 & 0,784 & 0,853 & 0,602 \\
\hline
\end{tabular}

Nota. DP (Desvio-padrão); CC (Confiabilidade Composta); AVE (Variância Extraída Média)

Em relação à validade das escalas dos construtos, foram realizadas três validades: fatorial, convergente e discriminante (Kline, 2011). A primeira foi feita por meio da observação dos coeficientes padronizados para cada item dos construtos, e todos apresentaram valores acima de 0,5 , comprovando a validade fatorial. A validade convergente foi investigada com base nos valores da AVE. Essa validade tem como medida de boa adequação valores acima de 0,5 , e é possível perceber, na Tabela 2, que todos os construtos atingiram esse valor.

Tabela 3. Correlações, variância compartilhada e AVE

\begin{tabular}{l|l|l|l|l}
\hline Variáveis & $\mathbf{P}$ & CA & EP & DA \\
\hline P & $\mathbf{0 , 5 2 9}$ & 0,076 & 0,025 & 0,022 \\
\hline CA & 0,277 & $\mathbf{0 , 6 5 2}$ & 0,128 & 0,024 \\
\hline EP & $-0,159$ & $-0,358$ & $\mathbf{0 , 5 6 7}$ & 0,046 \\
\hline DA & $-0,148$ & $-0,156$ & 0,216 & $\mathbf{0 , 6 0 2}$ \\
\hline
\end{tabular}

Nota. Os valores das AVEs estão na diagonal da tabela (em negrito), os valores abaixo da diagonal são as correlações e os acima são as variâncias compartilhadas (correlações ao quadrado).

Para verificar a validade discriminante, buscou-se comparar a AVE de cada construto com a variância compartilhada. Conforme Fornell e Larcker (1981), a AVE de um construto não deve apresentar uma elevada correlação com outros construtos, que são supostamente diferentes. Assim, os valores da AVE devem ficar acima das variâncias compartilhadas. A Tabela 3 mostra que essa condição foi atendida.

\section{Modelo estrutural}

A segunda etapa da MEE consiste na análise do modelo estrutural, para a qual são acrescentadas relações entre as variáveis latentes do modelo de mensuração. Assim, foram obtidos novos índices de ajustamento, podendo ser conferidos na Tabela 4. Pode-se afirmar que as medidas encontradas apresentam um bom ajustamento do modelo estrutural. 
Tabela 4. Índices de ajustamento do modelo

\begin{tabular}{|c|c|c|}
\hline Índices & Resultados & Critérios \\
\hline$x^{2} / G I(172,759 / 108)$ & 1,600 & {$[1 ; 2]$ Ajuste bom } \\
\hline$p$-value & 0,000 & $<0,05$ Ajuste aceitável* \\
\hline GFI & 0,933 & >0,9o Ajuste bom \\
\hline $\mathrm{IFI}$ & 0,955 & >o,95 Ajuste muito bom \\
\hline TLI & 0,942 & >o,95 Ajuste bom \\
\hline $\mathrm{CFI}$ & 0,954 & >0,95 Ajuste muito bom \\
\hline $\mathrm{NFI}$ & 0,887 & {$[0,80 ; 0,90]$ Ajuste aceitável } \\
\hline PCFI & 0,757 & {$[0,70 ; 0,80]$ Ajuste aceitável } \\
\hline RMSEA & 0,046 & $<0,05$ Ajuste muito bom \\
\hline PCLOSE & 0,664 & >0,05 Ajuste muito bom \\
\hline $\mathrm{EVCl}$ & 0,945 & Quanto menor, melhor \\
\hline $\mathrm{MEVCl}$ & 0,968 & Quanto menor, melhor \\
\hline
\end{tabular}

Nota. *Amostras grandes apresentam mais sensibilidade para ter significância no p-value.

Além desses, foi possível analisar os coeficientes entre as relações das variáveis latentes - Tabela 5 -, que permitem avaliar as hipóteses desenvolvidas. 0 p-value permite afirmar que apenas as relações das hipóteses $\mathrm{H}_{3}(-)$ e H6(-) apresentaram valores menores que 0,05 . Contudo, apenas a H6(-) pode ser considerada aceita ou suportada, porque atendeu também à valência negativa da relação. Isso não aconteceu com a $\mathrm{H}_{3}(-)$, que teve uma valência positiva do coeficiente de relação.

Destaca-se, ainda, que a $\mathrm{H}_{4}(-)$ poderia ser considerada marginalmente aceita se fosse considerado um $p$-value de 0,10. Mas, para este estudo, será considerado apenas o $p$-value de até 0,05. Com isso, essa hipótese também foi considerada refutada pela pesquisa.

Tabela 5. Testes das hipóteses da pesquisa

\begin{tabular}{|c|c|c|c|c|c|c|}
\hline Hipóteses & Coeficiente padronizado & Coeficiente não padronizado & S.E. & R.C. & $p$ & Status \\
\hline$H_{1}(+): P$---> DA & $-0,102$ & $-0,089$ & 0,070 & $-1,273$ & 0,203 & Não suportada \\
\hline $\mathrm{H}_{2}(-):$ CA $-->$ DA & $-0,065$ & $-0,039$ & 0,050 & $-0,782$ & 0,434 & Não suportada \\
\hline $\mathrm{H}_{3}(-): P$--->CA & 0,277 & 0,399 & 0,109 & 3,648 & 0,000 & Não suportada \\
\hline$H_{4}(-):$ EP ---> DA & 0,176 & 0,159 & 0,092 & 1,736 & 0,083 & Não suportada \\
\hline $\mathrm{H}_{5}(+): P$---> EP & $-0,064$ & $-0,062$ & 0,076 & $-0,816$ & 0,414 & Não Suportada \\
\hline H6(-): CA ---> EP & $-0,341$ & $-0,229$ & 0,061 & $-3,744$ & 0,000 & Suportada \\
\hline
\end{tabular}

Nota. p<0,05; Significância marginal = p<0,10; SE = Erro padrão; RC = Rácio Crítico. 


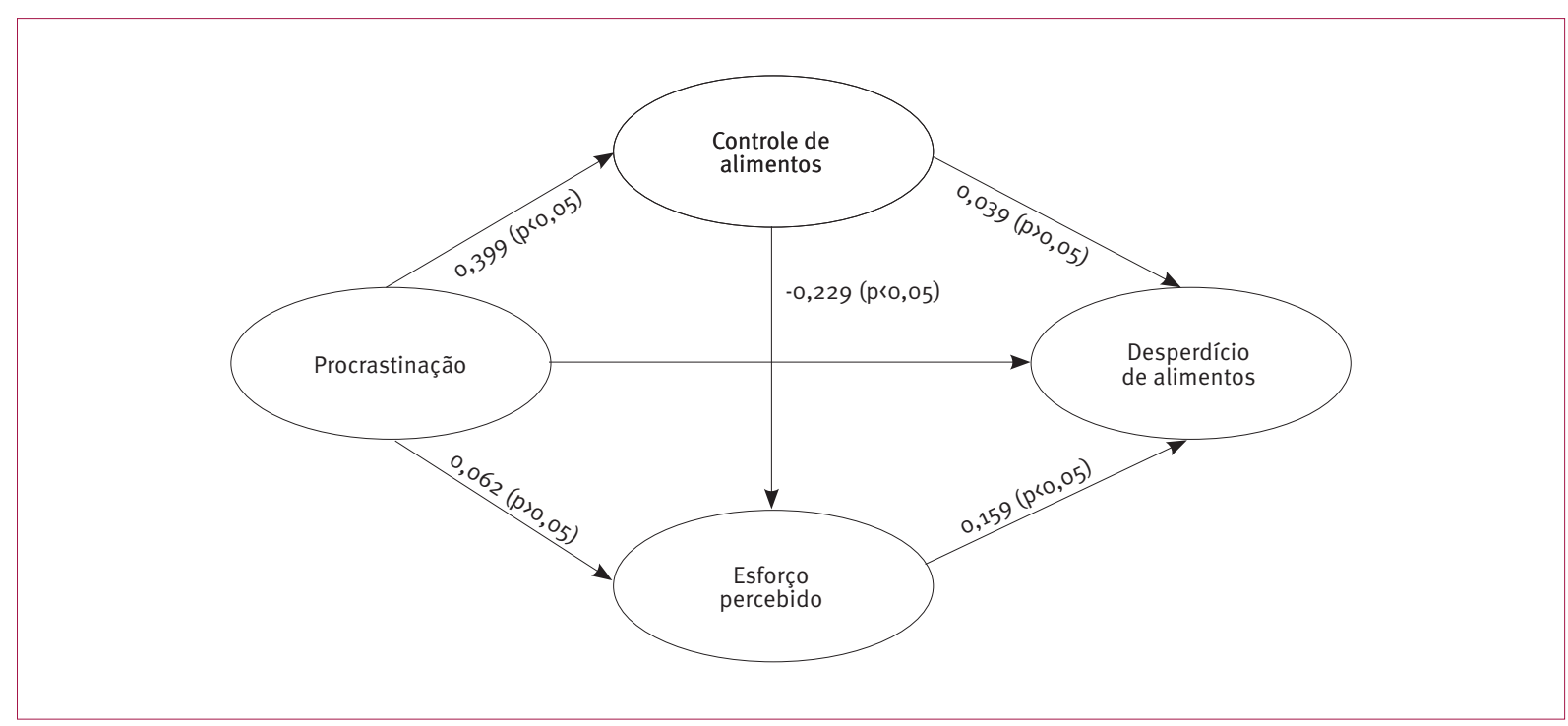

\section{Análises das hipóteses}

O foco em evitar o desperdício não é guiado por uma orientação a obter ganhos ambientais, como sugeriram alguns estudos (e.g. Diaz-Ruiz et al., 2018; Lillemo, 2014), mas a evitar perdas. Apesar de pesquisas anteriores sinalizarem uma relação positiva entre o comportamento de procrastinar e o desperdício de alimentos, a exemplo dos estudos de Blichfeldt et al. (2015) e de Porpino et al. (2016), o resultado da primeira hipótese ( $\mathrm{H}_{1}$ ) mostra-se contraintuitivo, visto que não foi suportada. Isso possivelmente é explicado devido à existência de um engajamento maior dos indivíduos em atividades com foco em evitar resultados negativos, ao invés de obtenção de ganhos (Massar et al., 2020). Assim, mesmo que possuam uma maior tendência à procrastinação, eles estão propensos a esforçar-se para aproveitar os alimentos em sua totalidade e procurar meios de prolongar seu tempo de vida útil, porquanto o desperdício resultaria na necessidade de dedicar mais tempo ao preparo de novas refeições e à realização de compras, e, conforme apontam Langan e Kumar (2019), a dedicação de tempo representa um alto custo.

Contudo, o maior controle de alimentos não possui relação com um menor desperdício. Esse resultado referente à hipótese $\mathrm{H}$ 2, que foi refutada, contribui para a validação do que apontam Terpstra et al. (2005) e Dobernig e Schanes (2019), os quais observaram que, mesmo os indivíduos afirmando possuírem controle dos alimentos, mantinham-nos armazenados de maneira inadequada. Assim, a gestão de alimentos, além de não ser considerada uma atividade rotineira (Romani et al., 2018), é realizada de modo ineficaz (Farr-Wharton et al., 2014), visto que, se esta fosse realizada adequadamente, resultaria em um menor desperdício (Kavanaugh \& Quinlan, 2020). Nesse sentido, o resultado aqui encontrado aponta que, possivelmente, mesmo realizando um alto controle, os indivíduos o fazem de maneira intuitiva, sem seguir as diretrizes das autoridades de saúde, resultando no desperdício. Portanto, configura-se como uma ação contraprodutiva.

Além disso, indica-se que, se o controle de alimentos é percebido como de baixa complexidade, pode ter uma maior propensão a ser realizado mesmo por indivíduos que tendem a procrastinar, porquanto mesmo a hipótese $\mathrm{H}_{3}$ - que buscou verificar se há uma relação negativa entre procrastinação e controle - não atendendo à valência do coeficiente de relação, possui significância estatística $(\beta=0,399, p<0,05)$. Assim, tem-se uma rela- 
ção diretamente proporcional. Esse resultado vai de encontro a pesquisas anteriores (e.g. Blichfeldt et al., 2015; Evans, 2011), contudo é factível, pela tendência de alguns indivíduos buscarem conforto psicológico, devido à procrastinação na realização de tarefas de acordo com seu nível de complexidade, estando inclinados a priorizar aquelas que requerem menor esforço cognitivo (Rusou et al., 2020).

Destaca-se que a habilidade de controle de alimentos pode atuar nessa relação, pois permite a visualização da tarefa como de menor esforço para ser realizada, evitando a procrastinação (Graham-Rowe et al., 2014). Além disso, conforme elucidam as teorias econômicas do processo de tomada de decisão (e.g. Hesse, Kangur, \& Hunt, 2020; Zeelenberg \& Dijk, 1997), quando se requer um menor esforço para realizar uma atividade, há um aumento no valor da recompensa, impulsionando a execução. Ressalta-se, ainda, que a ênfase em evitar perdas pode exercer um importante papel na realização do controle, mesmo por indivíduos que tendem a procrastinar, pois pode fomentar um maior engajamento (Massar et al., 2020). Logo, a iminência de perda, principalmente monetária, possivelmente, influencia os consumidores a controlarem os alimentos.

A relação da percepção de esforço e do desperdício de alimentos é destacada neste estudo por meio da hipótese H4. Previa-se que um maior esforço percebido resultaria em um menor desperdício de alimentos, contudo essa hipótese não foi suportada. Destaca-se, porém, que os resultados obtidos $(\beta=0,159 ; p=0,083)$ permitem uma reflexão, com parcimônia, acerca da relação positiva entre os construtos. Ao observar as médias do esforço percebido $(M=3,69)$ e do desperdício de alimentos $(M=2,44)$, verifica-se que os respondentes não percebem um grande esforço em realizar as atividades de armazenagem dos produtos e tendem a não desperdiçar. Por isso, com base no coeficiente da relação obtido, pode-se inferir que um menor esforço resulta em um menor desperdício de alimentos. Isso pode ocorrer porque um menor esforço pode associar-se à confiança no processo de armazenagem, reduzindo o medo de adoecer e ter uma intoxicação alimentar ao reutilizar sobras de refeições, por exemplo, e isso pode reverberar em um menor desperdício (Graham-Rowe et al., 2014).

Ademais, conforme indica o resultado da $\mathrm{H}_{5}$, mesmo que o comportamento de procrastinar dos indivíduos seja alto, isso não reflete em não realizar atividades ligadas a evitar o desperdício, que alteraria a percepção de esforço. Esse resultado é suportado por meio do que indicam os achados anteriores. Primariamente, devido às atividades relacionadas a evitar o desperdício de alimentos serem realizadas com foco em evitar perdas em termos de empenhar maiores esforços/recursos de tempo e dinheiro. Logo, como apontado, esse foco resulta em um maior engajamento (Massar et al., 2020). Além disso, porque atividades de gestão de alimentos possuem uma probabilidade alta de serem realizadas por serem percebidas como de baixa complexidade quando comparadas a outras incumbências, principalmente, de caráter intelectual, com as quais provavelmente a amostra desta pesquisa, que é representativa de indivíduos que estão cursando o ensino superior (69,2\%), lida diariamente.

A última hipótese, a H6, por sua vez, foi confirmada. Logo, como proposto, um maior controle de alimentos implica menor esforço percebido. Nota-se, assim, que o resultado é consoante com o preconizado por Dobernig e Schanes (2019), que elucidam essa relação por meio do exemplo da conveniência de morar próximo a supermercados de grande porte, o que possibilita - e, até, induz - a realização de compras em menor quantidade, mesmo que com frequência superior, o que permite um maior controle dos alimentos sem, necessariamente, incidir num aumento da percepção de esforço (Amirudin \& Gin, 2019), simultaneamente, incentivando a redução da intenção de descarte. Este e os demais achados desta investigação foram sintetizados na Tabela 6 com vistas a garantir uma melhor visualização das contribuições teóricas e gerenciais.

\section{Tabela 6. Síntese dos resultados}




\begin{tabular}{|c|c|c|}
\hline Hipótese & Implicação teórica & Implicação gerencial \\
\hline $\begin{array}{l}\mathbf{H}_{1}(+): \text { P ---> DA } \\
\text { (Não suportada) }\end{array}$ & $\begin{array}{l}\text { O foco em evitar o desperdício não } \\
\text { é a obtenção de ganhos, mas evitar } \\
\text { perdas. }\end{array}$ & $\begin{array}{l}\text { Campanhas publicitárias de conscientização devem focar-se em } \\
\text { ressaltar as perdas resultantes do desperdício, principalmente, a } \\
\text { iminente perda de tempo. }\end{array}$ \\
\hline $\begin{array}{l}\mathrm{H}_{2}(-): \text { CA ---> DA } \\
\text { (Não suportada) }\end{array}$ & $\begin{array}{l}\text { Maior controle é contraprodutivo } \\
\text { quando realizado de maneira } \\
\text { intuitiva. }\end{array}$ & $\begin{array}{l}\text { É necessário que os órgãos governamentais tracem estratégias para } \\
\text { propagar as diretrizes de armazenagem e higienização de alimentos } \\
\text { para informar melhor a população, e, sobretudo, instruir no controle } \\
\text { adequado de cada categoria de alimento. }\end{array}$ \\
\hline $\begin{array}{l}\mathrm{H}_{3}(-): \mathrm{P} \mathrm{--->CA} \\
\text { (Não suportada) }\end{array}$ & $\begin{array}{l}\text { A habilidade de controlar alimentos } \\
\text { e a iminência de perda monetária } \\
\text { pode levar ao engajamento no } \\
\text { controle. }\end{array}$ & $\begin{array}{l}\text { Propagandas devem elucidar a perda monetária no desperdício } \\
\text { de alimentos e deve-se propagar instruções de controle, pois, } \\
\text { possivelmente, isso fomenta um maior engajamento dos } \\
\text { consumidores no processo. }\end{array}$ \\
\hline $\begin{array}{l}\text { H4(-): EP ---> DA } \\
\text { (Não suportada) }\end{array}$ & $\begin{array}{l}\text { O menor esforço percebido pode } \\
\text { associar-se à confiança no processo } \\
\text { de armazenagem, reduzindo o } \\
\text { desperdício de alimentos. }\end{array}$ & $\begin{array}{l}\text { As instruções nos rótulos dos produtos para armazenagem devem ser } \\
\text { claras e mais bem evidenciadas, pois sinaliza-se que a facilidade da } \\
\text { ação pode possibilitar reduzir o desperdício de alimentos. }\end{array}$ \\
\hline $\begin{array}{l}\mathrm{H}_{5}(+) \text { : P -.-> EP } \\
\text { (Não suportada) }\end{array}$ & $\begin{array}{l}\text { O foco em evitar empenhar esforços } \\
\text { futuros e a percepção de baixa } \\
\text { complexidade do controle de } \\
\text { alimentos permitem que ações } \\
\text { para reduzir o desperdício sejam } \\
\text { prioritárias, e não procrastinadas. }\end{array}$ & $\begin{array}{l}\text { Treinar a população a controlar os alimentos mostra-se eficaz ao } \\
\text { evidenciar a sua baixa complexidade, reduzindo o esforço percebido. } \\
\text { Isso pode ser realizado por meio de abertura de editais que fomentem } \\
\text { projetos de extensão nas universidades públicas, com ênfase à área } \\
\text { de nutrição. }\end{array}$ \\
\hline $\begin{array}{l}\text { H6(-): CA ---> EP } \\
\text { (Suportada) }\end{array}$ & $\begin{array}{l}\text { O maior controle de alimentos } \\
\text { resulta em um menor esforço } \\
\text { percebido. }\end{array}$ & $\begin{array}{l}\text { Políticas públicas devem inserir na pauta a promoção de maior } \\
\text { acessibilidade aos produtos alimentícios com vistas a garantir menor } \\
\text { percepção de esforço. Além disso, é importante que os consumidores } \\
\text { realizem um planejamento da rotina de compras. Isso possibilita } \\
\text { maior controle e pode auxiliar a redução do esforço percebido. }\end{array}$ \\
\hline
\end{tabular}

\section{CONCLUSÃO}

Dada a emergente necessidade de compreender as variáveis que permeiam o desperdício de alimentos, este estudo apresenta-se como um esforço a essa causa, partindo do pressuposto de que há uma influência significativa de fatores psicossociais no comportamento dos consumidores. Buscou-se analisar as relações entre a procrastinação e o desperdício de alimentos, bem como as relações do controle dos produtos no âmbito domiciliar e o esforço percebido quanto à gestão dos alimentos, mediante uma MEE.

Os principais resultados encontrados expandem o estado da arte por serem considerados contraintuitivos teoricamente, porquanto a procrastinação não possui relação positiva com o comportamento de desperdício de alimentos, e, mesmo com uma alta propensão a procrastinar, os indivíduos empenham-se em controlar os alimentos, possivelmente, por perceberem essa atividade como de baixa complexidade, atenuando, assim, o esforço percebido. Além disso, destaca-se que um maior controle de alimentos e maior esforço percebido não resultam, necessariamente, em um menor desperdício.

Portanto, identifica-se que o foco em empenhar esforços para diminuir o desperdício de alimentos pode não estar embasado em obter ganhos em termos de sustentabilidade, mas em evitar perdas de recursos monetários e de tempo. Isso, combinado à percepção de baixa complexidade da atividade, estimula os consumidores a não procrastinarem. Nesse sentido, este estudo corrobora as teorias econômicas do processo de tomada de decisão que preveem tal ênfase. Ressalta-se, ainda, que a percepção de menor esforço no controle de alimentos e a iminência de perda monetária devido ao desperdício, possivelmente, levam a um maior engajamento na gestão dos alimentos. Porém, destaca-se que um maior controle não resulta necessariamente em um menor desperdício, se for realizado com base no senso comum. 
Como principais implicações práticas, ressalta-se que há uma urgência em difusão das práticas adequadas de controle, como também de uma maior acessibilidade a informações sobre a armazenagem dos produtos. De maneira prática, pode-se utilizar campanhas de conscientização e distribuição de cartilhas que orientem os consumidores a armazenarem e higienizarem os produtos. Ademais, promover treinamentos para consolidar as informações difundidas e estimular a um controle regular, uma vez que isso pode atenuar a percepção de esforço e, consequentemente, a probabilidade de desperdício.

Apesar das contribuições teóricas e práticas obtidas por meio deste estudo, algumas limitações são delineadas. Em primeira instância, há uma homogeneidade da amostra obtida, apesar da tentativa de heterogeneidade. Isso porque obtiveram-se níveis de renda, estado civil, idade e nível educacional muito similares. Ademais, seus resultados estão pautados em evidências provenientes de um corte transversal que, talvez, pudessem diferir se realizada uma investigação longitudinal. Essa última limitação é apontada como uma sugestão para estudos futuros. A escala de procrastinação também apresentou deficiências de consistência interna, sendo necessária a retirada de vários itens. Possivelmente, esses problemas ocorreram por causa da estrutura dos itens, que podem ter uma conotação semântica diferente em outras nacionalidades após a tradução.

Pesquisas futuras podem, também, tecer considerações sobre reposicionar as variáveis aqui estudadas, uma vez que o modelo apresentou uma estrutura estatística com bons índices de ajustes. Logo, sugere-se relacionar o esforço percebido como variável que afeta negativamente o controle de alimentos e a procrastinação, sendo essas relações resultantes no comportamento de desperdício de alimentos. Outrossim, um estudo pode ser comparativo à amostra apresentada, sendo o modelo explicativo proposto relacionado a indivíduos de menor nível de escolaridade, renda alta e com idade acima de 40 anos.

\section{REFERÊNCIAS}

Abdelradi, F. (2018). Food waste behaviour at the household level: A conceptual framework. Waste Management, 71, 485493. doi: 10.1016/j.wasman.2017.10.001

Ahn, J., Lee, C. K., Back, K. J., \& Schmitt, A. (2019). Brand experiential value for creating integrated resort customers' co-creation behavior. International Journal of Hospitality Management, 81, 104-112. doi: 10.1016/j.ijhm.2019.03.009

Aitken, R., Watkins, L., Williams, J., \& Kean, A. (2020). The positive role of labelling on consumers' perceived behavioural control and intention to purchase organic food. Journal of Cleaner Production, 255, 120334. doi: 10.1016/j.jclepro.2020.120334

Akerlof, G. A. (1991). Procrastination and obedience. The American Economic Review, 81(2), 1-19. Retrived from: https:// www.jstor.org/stable/2006817

Aktas, E., Sahin, H., Topaloglu, Z., Oledinma, A., Huda, A. K. S., Irani, Z., ... Kamrava, M. (2018). A consumer behavioural approach to food waste. Journal of Enterprise Information Management, 31(5), 658-673. doi:10.1108/JEIM-03-2018-0051

Amirudin, N., \& Gim, T. H. T. (2019, May). Impact of perceived food accessibility on household food waste behaviors: A case of the Klang Valley, Malaysia. Resources, Conservation and Recycling, 151, 104335. doi: 10.1016/j.resconrec.2019.05.011

Aschemann-Witzel, J., Giménez, A., \& Ares, G. (2019). Household food waste in an emerging country and the reasons why: Consumer's own accounts and how it differs for target groups. Resources, Conservation and Recycling, 145, 332-338. doi: 10.1016/j.resconrec.2019.03.001
Aschemann-Witzel, J., Hooge, I. De, Amani, P., Bech-Larsen, T., \& Oostindjer, M. (2015). Consumer-related food waste: Causes and potential for action. Sustainability, 7(6), 6457-6477. doi: $10.3390 /$ su7066457

Banović, M., Krystallis, A., Guerrero, L., \& Reinders, M. J. (2016). Consumers as co-creators of new product ideas: An application of projective and creative research techniques. Food Research International, 87, 211-223. doi: 10.1016/j. foodres.2016.07.010

Benfer, N., Bardeen, J. R., \& Clauss, K. (2018). Experimental manipulation of emotion regulation self-efficacy: Effects on emotion regulation ability, perceived effort in the service of regulation, and affective reactivity. Journal of Contextual Behavioral Science, 10, 108-114. doi: 10.1016/j. jcbs.2018.09.006

Blichfeldt, B. S., Mikkelsen, M., \& Gram, M. (2015). When it stops being food: The edibility, ideology, procrastination, objectification and internalization of household food waste. Food, Culture and Society, 18(1), 89-105. doi: 10.2752/175174 415X14101814953963

Brehm, J. W., Wright, R. A., Solomon, S., Silka, L., \& Greenberg, J. (1983). Perceived difficulty, energization, and the magnitude of goal valence. Journal of Experimental Social Psychology, 19(1), 21-48. doi: 10.1016/0022-1031(83)90003-3

Carmo, I. S., \& Barcellos, M. D. (2018). Drivers and barriers to food waste reduction. British Food Journal, 120(10), 23642387. https://doi.org/10.1108/BFJ-12-2017-0726 
Chen, Z., Liu, P., Zhang, C., \& Feng, T. (2020). Brain morphological dynamics of procrastination: The crucial role of the self-control, emotional, and episodic prospection network. Cerebral Cortex, 30(5), 2834-2853. doi: 10.1093/cercor/bhz278

Churchill, G. A. (1999). Marketing research (7th ed.). Orlando, USA: The Dryden Press.

Costa, M. F., Farias, S. A., \& Angelo, C. F. (2018). Chronic regulatory focus: Resist impulse consumption or let it happen? Revista Brasileira de Gestão de Negócios, 20, 619-637. doi: 10.7819/ rbgn.voio.3954

Diaz-Ruiz, R., Costa-Font, M., \& Gil, J.M. (2018). Moving ahead from food-related behaviours. An alternative approach to understand household food waste generation. Journal of Cleaner Production, 172, 1140-1151. doi: 10.1016/j. jclepro.2017.10.148

Dobernig, K., \& Schanes, K. (2019). Domestic spaces and beyond: Consumer food waste in the context of shopping and storing routines. International Journal of Consumer Studies, 43(5), 480-489. doi: 10.1111/ijcs.12527

Evans, D. (2011). Blaming the consumer - Once again: The social and material contexts of everyday food waste practices in some English households. Critical Public Health, 21(4), 429440. doi: 10.1080/09581596.2011.608797

Farr-Wharton, G., Foth, M., \& Choi, J. H. J. (2014). Identifying factors that promote consumer behaviours causing expired domestic food waste. Journal of Consumer Behaviour, 13(6), 393-402. doi: 10.1002/cb.1488

Food and Agriculture Organization of the United Nations. (2018). The state of food security and nutrition in the world. Retrieved from http://www.fao.org/3/ca5162en/ca5162en.pdf

Fornell, C., \& Larcker, D. F. (1981). Evaluating structural equation models with unobservable variables and measurement error. Journal of Marketing Research, 18(1), 39-50. doi: 10.1177/002224378101800104

Gamst-Klaussen, T., Steel, P., \& Svartdal, F. (2019). Procrastination and personal finances: Exploring the roles of planning and financial self-efficacy. Frontiers in Psychology, 10, 775. doi: $0.3389 /$ fpsyg.2019.00775

Graham-Rowe, E., Jessop, D. C., \& Sparks, P. (2014). Identifying motivations and barriers to minimising household food waste. Resources, Conservation and Recycling, 84, 15-23. doi: 10.1016/j.resconrec.2013.12.005

Hair, J., Anderson, R., Taham, R., \& Black, W. (2010). Análise multivariada de dados (6th ed.). Porto Alegre, RS: Bookman.

Harmon-Jones, E., Willoughby, C., Paul, K., \& Harmon-Jones, C. (2020). The effect of perceived effort and perceived control on reward valuation: Using the reward positivity to test a dissonance theory prediction. Biological Psychology, 154, 107910. doi: 10.1016/j.biopsycho.2020.107910

Hartmann, C., Dohle, S., \& Siegrist, M. (2013). Importance of cooking skills for balanced food choices. Appetite, 65, 125-131. doi: 10.1016/j.appet.2013.01.016

Hebrok, M., \& Boks, C. (2017). Household food waste: Drivers and potential intervention points for design - An extensive review. Journal of Cleaner Production, 151, 380-392. doi: 10.1016/j.jclepro.2017.03.069v

Hesse, C., Kangur, K., \& Hunt, A. R. (2020). Decision making in slow and rapid reaching: Sacrificing success to minimize effort. Cognition, 205(104426), 1-18. doi: 10.1016/j. cognition.2020.104426
Holsteijn, F. Van, \& Kemna, R. (2018). Minimizing food waste by improving storage conditions in household refrigeration. Resources, Conservation and Recycling, 128, 25-31. doi: 10.1016/j.resconrec.2017.09.012

Ilyuk, V. (2018). Like throwing a piece of me away: How online and in-store grocery purchase channels affect consumers' food waste. Journal of Retailing and Consumer Services, 41, 20-30. doi: 10.1016/j.jretconser.2017.11.003

Inzlicht, M., Shenhav, A., \& Olivola, C. Y. (2018). The effort paradox: Effort is both costly and valued. Trends in Cognitive Sciences, 22(4), 337-349. doi: 10.1016/j.tics.2018.01.007

Jacobsen, L. F., Tudoran, A. A., \& Martinez, M. G. (2020). Examining trust in consumers as new food co-creators: Does the communicator matter? Food Quality and Preference, 86, 104004. doi: 10.1016/j.foodqual.2020.104004

Kallmuenzer, A., Peters, M., \& Buhalis, D. (2019). The role of family firm image perception in host-guest value co-creation of hospitality firms. Current Issues in Tourism, 1-18. doi: $10.1080 / 13683500.2019 .1611746$

Kameke, C. Von, \& Fischer, D. (2018). Preventing household food waste via nudging: An exploration of consumer perceptions. Journal of Cleaner Production, 184, 32-40. doi: 10.1016/j. jclepro.2018.02.131

Kavanaugh, M., \& Quinlan, J. J. (2020). Consumer knowledge and behaviors regarding food date labels and food waste. Food Control, 115, 107285. doi: 10.1016/j.foodcont.2020.107285

Kline, R. B. (2011). Principles and practice of structural equation modeling. New York, USA: Guilford.

Langan, R., \& Kumar, A. (2019). Time versus money: The role of perceived effort in consumers' evaluation of corporate giving. Journal of Business Research, 99, 295-305. doi: 10.1016/j. jbusres.2019.02.016V

Lee, K. C. L. (January, 2018). Grocery shopping, food waste, and the retail landscape of cities: The case of Seoul. Journal of Cleaner Production, 172, 325-334. doi: 10.1016/j. jclepro.2017.10.085

Lillemo, S. C. (2014). Measuring the effect of procrastination and environmental awareness on households' energy-saving behaviours: An empirical approach. Energy Policy, 66, 249256. doi: 10.1016/j.enpol.2013.10.077

Liu, G., Cheng, G., Hu, J., Pan, Y., \& Zhao, S. (2020). Academic self-efficacy and postgraduate procrastination: A moderated mediation model. Frontiers in Psychology, 11, 1752. doi: 10.3389/fpsyg.2020.01752

Malhotra, N. K. (2012). Pesquisa de marketing: Uma orientação aplicada. São Paulo, SP: Editora Bookman.

Marklinder, I. M., Lindblad, M., Eriksson, L. M., Finnson, A. M., \& Lindqvist, R. (2004). Home storage temperatures and consumer handling of refrigerated foods in Sweden. Journal of Food Protection, 67(11), 2570-2577. doi: 10.4315/0362-028X-67.11.2570

Marôco, J. (2014). Análise de equações estruturais: Fundamentos teóricos, software e aplicações ( $2^{\underline{a}}$ ed.). Perô Pinheiro, Portugal: Report Number.

Massar, S. A., Pu, Z., Chen, C., \& Chee, M. W. (2020). Losses motivate cognitive effort more than gains in effort-based decision making and performance. Frontiers in Human Neuroscience, 14, 287. doi: 10.3389/fnhum.2020.00287

Masson, M., Delarue, J., \& Blumenthal, D. (2017). An observational study of refrigerator food storage by consumers in controlled conditions. Food Quality and Preference, 56, 294-300. doi: 10.1016/j.foodqual.2016.06.010 
Modig, E., Dahlén, M., \& Colliander, J. (2014). Consumer-perceived signals of 'creative' versus 'efficient' advertising: Investigating the roles of expense and effort. International Journal of Advertising, 33(1), 137-154. doi: 10.2501/IJA-33-1-137-154

Mohr, L. A., \& Bitner, M. J. (1995). The role of employee effort in satisfaction with service transactions. Journal of Business Research, 32(3), 239-252. doi: 10.1016/0148-2963(94)00049-K

Neubig, C. M., Vranken, L., Roosen, J., Grasso, S., Hieke, S., Knoepfle, S., ... Masento, N. A. (2020). Action-related information trumps system information: Influencing consumers' intention to reduce food waste. Journal of Cleaner Production, 261, 121126. doi: 10.3389/fnhum.2020.00287

Papargyropoulou, E., Lozano, R., Steinberger, J. K., Wright, N., \& Ujang, Z. B. (2014). The food waste hierarchy as a framework for the management of food surplus and food waste. Journal of Cleaner Production, 76, 106-115. doi: 1016/j. jclepro.2014.04.020

Parfenova, A., \& Romashova, S. (2019). The role of procrastination in students' consumer behavior: Budget planning and impulse buying. International Journal of Sociology and Social Policy, 40(1/2), 133-144. doi: 10.1108/IJSSP-10-2019-0199v

Patra, D., Leisnham, P. T., Tanui, C. K., \& Pradhan, A. K. (2020). Evaluation of global research trends in the area of food waste due to date labeling using a scientometrics approach. Food Control, 115, 107307. doi: 10.1016/j.foodcont.2020.107307

Porpino, G., Parente, J., \& Wansink, B. (2015). Food waste paradox: Antecedents of food disposal in low income households. International Journal of Consumer Studies, 39(6), 619-629. doi: 10.1111/ijcs.12207

Porpino, G., Wansink, B., \& Parente, J. (2016). Wasted positive intentions: The role of affection and abundance on household food waste. Journal of Food Products Marketing, 22(7), 733751. doi: 10.1080/10454446.2015.1121433

Raats, M. M., Shepherd, R., \& Sparks, P. (1995). Including moral dimensions of choice within the structure of the theory of planned behavior. Journal of Applied Social Psychology, 25(6), 484-494. doi: 10.1111/j.1559-1816.1995.tbo1763.x

Radzyminska, M., Jakubowska, D., \& Staniewska, K. (2016). Consumer attitude and behaviour towards food waste. Journal of Agribusiness and Rural Development, 1(39). doi: 10.17306/ JARD.2016.20

Richter, B. (2017). Knowledge and perception of food waste among German consumers. Journal of Cleaner Production, 166, 641-648. doi: 10.1016/j.jclepro.2017.08.009

Romani, S., Grappi, S., Bagozzi, R. P., \& Barone, A. M. (2018). Domestic food practices: A study of food management behaviors and the role of food preparation planning in reducing waste. Appetite, 121, 215-227. doi: 10.1016/j. appet.2017.11.093
Rusou, Z., Amar, M., \& Ayal, S. (2020). The psychology of task management: The smaller tasks trap. Judgment and Decision Making, 15(4), 586-599. doi: 10.1016/j.ergon.2016.09.011

Russell, S. V., Young, C. W., Unsworth, K. L., \& Robinson, C. (2017). Bringing habits and emotions into food waste behaviour. Resources, Conservation and Recycling, 125, 107-114. doi: 10.1016/j.resconrec.2017.06.007

Schanes, K., Dobernig, K., \& Gözet, B. (2018). Food waste matters: A systematic review of household food waste practices and their policy implications. Journal of Cleaner Production, 182, 978-991. doi: 10.1016/j.jclepro.2018.02.030

Stancu, V., Haugaard, P., \& Lähteenmäki, L. (2016). Determinants of consumer food waste behaviour: Two routes to food waste. Appetite, 96, 7-17. doi: 10.1016/j.appet.2015.08.025

Steel, P. (2010). Arousal, avoidant and decisional procrastinators: Do they exist? Personality and Individual Differences, 48(8), 926-934. doi: 10.1016/j.paid.2010.02.025

Tanaka, J. S. (1987). "How big is big enough?": Sample size and goodness of fit in structural equation models with latent variables. Child Development, 58(1), 134-146. doi: $10.2307 / 1130296$

Terpstra, M. J., Steenbekkers, L. P. A., Maertelaere, N. C. M. De, \& Nijhuis, S. (2005). Food storage and disposal: Consumer practices and knowledge. British Food Journal, 107(7), 526533. doi: 10.1108/00070700510606918

Tuckman, B. W. (1990). Measuring procrastination attitudinally and behaviorally. Boston, USA: ERIC.

Woensel, T. V., Donselaar, K. V., Broekmeulen, R., \& Fransoo, J. (2007). Consumer responses to shelf out-of-stocks of perishable products. International Journal of Physical Distribution \& Logistics Management, 37, 704-718. doi: 10.1108/09600030710840822

Yen, C.-H., Teng, H.-Y., \& Tzeng, J.-C. (2020). Innovativeness and customer value co-creation behaviors: Mediating role of customer engagement. International Journal of Hospitality Management, 88, 102514. doi: 10.1016/j.ijhm.2020.102514V

Zanjani, S. H., Milne, G. R., \& Miller, E. G. (2016). Procrastinators' online experience and purchase behavior. Journal of the Academy of Marketing Science, 44(5), 568-585. doi: 10.1007/ s11747-015-0458-1

Zeelenberg, M., \& Dijk, E. Van. (1997). A reverse sunk cost effect in risky decision making: Sometimes we have too much invested to gamble. Journal of Economic Psychology, 18(6), 677-691. doi: 10.1016/S0167-4870(97)00029-9v

Zhu, M., Bagchi, R., \& Hock, S. J. (2019). The mere deadline effect: Why more time might sabotage goal pursuit. Journal of Consumer Research, 45(5), 1068-1084. doi: 10.1093/jcr/ ucyozo

\section{CONTRIBUIÇÃO DOS AUTORES}

Marconi Freitas da Costa e Patrícia de Oliveira Campos trabalharam na conceitualização e abordagem teóricametodológica. A revisão teórica foi conduzida pela Patrícia de Oliveira Campos e Poliana Nunes de Santana. A coleta de dados foi coordenada por Patrícia de Oliveira Campos. Participaram da análise de dados Marconi Freitas da Costa, Patrícia de Oliveira Campos e Poliana Nunes de Santana. Todos os autores participaram da redação e revisão final do manuscrito. 